\title{
Developing Effective Faculty Competencies For Teaching International Business Topics
}

Jerry E. Wheat, (E-mail: jwheat@ius.edu), Indiana University Southeast

Brenda S. Swartz, (E-mail: bswartz@ius.edu), Indiana University Southeast

G. Rick French, (E-mail: Gfrench@ius.edu), Indiana University Southeast

\begin{abstract}
Faculty are increasingly called upon to teach topics in international business. To ensure teaching success, faculty need to develop knowledge of countries, international organizations, economies, culture, interpersonal skills in international settings, and foreign business practices. The purpose of the paper is to demonstrate how faculty can obtain the skills and knowledge necessary to teach international topics efficiently and cost effectively.
\end{abstract}

\section{Introduction}

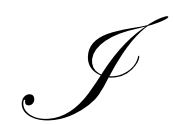

\section{len} for business programs to prepare students for the global environment. The American Assembly of Collegiate Schools of Business (AACSB) requires international topics as part of the business school curriculum but does not specify how to include the material in coursework. The guidelines require coverage of global issues to provide an understanding of perspectives that form the context for business (AACSB, 2000, p. 17). Academic institutions have budgetary constraints, which limit the ability of the business program to finance faculty development activities to teach these global issues. This challenges the creativity of faculty in meeting the AACSB guidelines. The traditional approach to enroll in seminars or short courses on the material to be taught is a traditional strategy for developing faculty. This paper explores additional creative ways to internationalize faculty, with an emphasis on nontraditional activities that are useful to any educational institution, but particularly those with constrained resources. There are a variety of resources to assist faculty in acquiring international expertise. Programs involving federal agencies, businesses, non-profit organizations, and local community groups can provide international exposure for faculty. Faculty teaching international topics need to explore these opportunities, participate in the programs, incorporate them into classroom activities, and assess their impact on students' educational experiences.

\section{AACSB Guidelines}

The AACSB has supported a variety of approaches in preparing students to participate in the global business environment. Some institutions offer stand-alone international or global business courses required for all business school students. Other institutions interweave international issues into one or more required core courses such as accounting, finance, management, marketing, or production. Students with greater international interests are often encouraged to enroll in advanced international courses and to travel abroad for intensive semester or yearlong internships. Many schools offer a combination of these experiences to prepare students for professional cross-cultural international business responsibilities. Business faculty teaching students in these courses or collaborating with on more intensive projects abroad need to have significant international experience to be effective mentors.

Readers with comments or questions are encouraged to contact the authors via email. 
Successful faculty must have a broad cultural understanding of the global business environment. Faculty must develop specialized knowledge and skills to be able to teach about successful international firms, cross-cultural perspectives, and the international business environment. Faculty need general and some specific knowledge of individual countries and their economies, as well as understanding the origins and workings of international organizations. It is necessary to understand other cultures and the specialized skills necessary to function successfully. Effective interpersonal skills and an understanding of business practices are essential to succeed in a multi-cultural environment. Faculty development should recognize the need to acquire this basic knowledge and skill set as a prerequisite to teaching international coursework. Most faculty have received little or no academic training in teaching international topics, and few have professional experience in the international arena. Business schools need to adopt a faculty development plan to enhance competencies and engender interest in international business. An effective plan should integrate international topics into the business curriculum and identify faculty members with expertise in the different areas to be taught.

If a university has a strong internationally oriented arts and science program, a business school may be able to augment its international program using international and language coursework that meets the general education requirements. Business schools can collaborate with other segments of the university to enhance international education in the entire university and optimize the use of scarce resources. Business faculty will need to provide colleagues in other departments with international business examples. Business faculty should also take advantage of the international cultural and political expertise of other faculty members.

Within the business school decisions need to be made about which courses are to be internationalized. AACSB allows schools to develop integrated stand-alone courses with international topics (AACSB, 2000). Many international topics are easily interwoven into the course, such as international examples in economics courses. Discussion of other material, such as the European Union or NAFTA, may need greater emphasis to provide adequate coverage. Some material is important enough to require a stand-alone course. For instance, technical international finance courses with complex international regulations and strategies are often offered as a separate course.

Current textbooks in core business courses typically include international material throughout the book. This development is driven by the AACSB requirement to include coverage of global issues in the curriculum and increasing U.S. business involvement in international business. In the past, texts often included international topics in a separate chapter in the back of the book. International material was not integrated throughout the text and students were left without a thorough understanding of its relevancy to the rest of the course. Faculty often did not teach the international material because of time constraints or a lack of expertise in this area. Inclusion of the material throughout texts has sparked greater student interest in global issues and assisted faculty with little international experience to see its importance and relationship with other topics in their disciplines.

Business schools need to identify instructors to teach this new body of international material and ascertain the credentials and experience needed to be effective. The expertise necessary to teach international topics will depend upon the emphasis placed upon international topics. When a stand-alone international business course is offered, the instructor needs significant depth of international expertise to be successful. The stand-alone course should be complemented by individual courses that re-emphasize issues of international business and their importance to the specific business discipline. Instructors offering these complementary courses should have an understanding of the international issues, but they do not need the high level of in-depth knowledge possessed by the instructor of the primary course. If interwoven into the various core courses, instructors will need a greater level of international expertise to be successful in teaching these topics. There often is a significant challenge in developing an interest and competency for teaching international business among faculty when this is not their primary area of research or academic experience.

Business schools initially need to identify the current international expertise of faculty. Some may have had international business course work and foreign travel as part of their undergraduate or graduate experience. Other faculty may have had foreign business experience working with a company or consulting with a foreign government. Faculty may have taught courses or traveled extensively outside the U.S. Some faculty may have pub- 
lished research or attended conferences focusing on international or cross-cultural issues. Foreign-born faculty may be effective international business instructors, but they still need to be evaluated on a case-by-case basis. The more effective international business instructors have synthesized their extensive international experience and are able to help students do the same.

\section{Resources for Internationalizing Faculty}

Faculty development plans may include formal, external activities or internal, less formal activities. Faculty may attend teaching seminars designed to augment their knowledge about a topic and teaching strategy. The following suggestions for formal, external programs will assist faculty in broadening their international expertise. Following sections of the paper discuss options for innovative university and community-based learning opportunities.

\section{External Resources for Faculty Development}

The U.S. Department of Education (DOE) funds 28 Centers for Business Education and Research (CIBER) at universities around the country. Universities with CIBER grants are required to provide international information to businesses and/or university faculty. Institutions may undertake a wide variety of activities to meet this requirement, including seminars on geographical business interests or on specific international topics. The U.S. Department of Education also offers Title 6 grants, which can be used to internationalize faculty in languages and customs of different countries.

To meet their CIBER requirements, some universities offer faculty development programs in international business. These activities have developed differently on each campus; however, the common goal is to offer programs to aid faculty in acquiring the expertise to teach international business courses. For example, the University of South Carolina, the University of Southern California, the University of Memphis, and Indiana University are some of the institutions that host faculty development programs through their CIBER programs. Other universities meet CIBER requirements by offering international travel and study programs for faculty that have a particular geographic interest. Some schools focus their international programs on specific regions of the world, such as the following: 1) Texas A\&M offers travel/study in Latin America, 2) the University of Hawaii focuses on Asia, and 3) the University of South Carolina has offers a study tour in Eastern Europe. Many of these programs require an extensive commitment by faculty and/or students. Faculty attending one or more of these programs can benefit all of their colleagues across the university. Faculty attending these programs may wish to publish research based on their experiences or make formal/informal presentations to the business faculty and students groups. Faculty often build continuing relationships with colleagues at foreign institutions, which may generate collaborative research efforts and foster student and faculty exchanges. Some of the CIBER programs also attract business people, which encourages faculty to become acquainted with firms who are dealing with international issues on a daily basis. Contact with international business may also result in student or faculty internships. CIBER programs may also offer partial or full scholarships for faculty participation in program activities.

Participation in conferences sponsored by international professional associations, such as the Academy of International Business or the International Trade and Finance Association or in the international sections of discipline-oriented organizations, offers access to current research on global issues and the opportunity to network with other international academicians. Relationships established with other participants at these conferences frequently result in foreign teaching opportunities during the summer or sabbaticals. The Fulbright Scholarship Program provides extensive opportunities for teaching and research at foreign universities. Faculty at many universities may combine a sabbatical leave with a Fulbright Award which allows them to spend significant time abroad.

\section{University-Based International Development Opportunities}

An assessment of the international resources on each campus should be completed to understand what international development opportunities are available. Foreign-born faculty and other colleagues with extensive study/work experience in other countries can be a great source of cultural and business information. Several oppor- 
tunities for international faculty development are presented in Exhibit 1 and discussed in the remainder of this section. Visiting foreign faculty that are on campus for lectures or more extensive commitments often welcome the opportunity to talk about their home country and to learn more about the U.S. Many universities have "Summer Abroad" programs for students. These programs can be broadened with faculty input to include meaningful opportunities for business students.

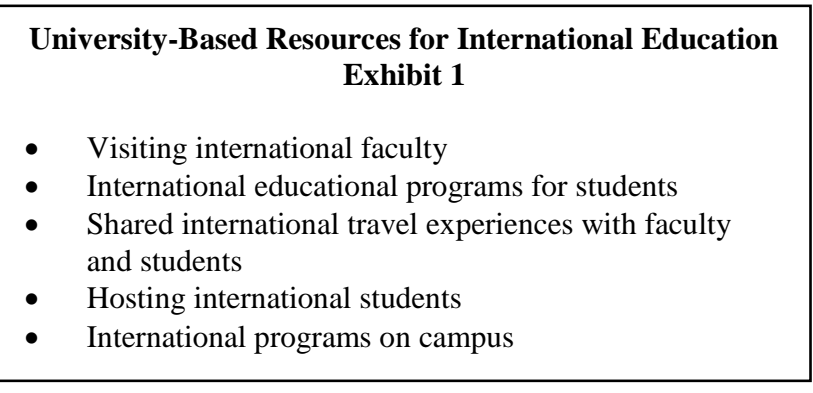

Faculty and students may have opportunities to learn from international students. Students and faculty returning from international programs and conferences should have opportunities to share what they have learned. Faculty can learn about international issues by being a host family for international students, which is a way to learn about another culture in a nonthreatening environment. A campus international program featuring a variety of ethnic foods, music, costume and dance brings the foreign students center stage and gives students and faculty the opportunity to reach out and learn something about another person and his culture.

\section{Community-Based International Development Opportunities}

Several opportunities for international faculty development are presented in Exhibit 2 and discussed in the remainder of this section. Faculty may capitalize on current international economic activity in their communities. Developing relations with U.S. businesses that export products or source raw materials overseas is a way for faculty to gather information to support research and teaching. Companies frequently view business faculty as a resource and are keen to engage them on consulting projects or to obtain useful information. These companies may provide internships and scholarships that give students real-world exposure to international business and increases their port-

\section{Community-Based Resources \\ For International Education Exhibit 2}

- International business activities in the community

- International student/faculty internships and scholarships

- International job opportunities for graduates

- Interaction with foreign nationals assigned to local businesses

- Religious groups with overseas missions

- Recent immigrants

faculty with international people and business activities. folio of skills. After graduation, the companies often provide job opportunities for graduates, particularly if candidates have knowledge or experience relating to areas of the world where they have business interests.

For a variety of reasons, the U.S. has attracted much direct foreign investment over the past two decades. When the initial investment is made, the foreign company typically sends foreign nationals to build the plant and start their operations. A smaller number of foreign nationals are retained at these facilities to support continuing operations. These foreign businessmen provide opportunities for local employers to connect

There are many non-business venues that faculty may use to develop their international expertise. Many religious groups have overseas missions and regularly send and receive international visitors. Foreign visitors may offer different views of other cultures. Recent immigrant groups who desire to become "Americanized" and enjoy discussing their homeland and are typically very eager and willing to share insights about their culture. Contact with faculty creates a win-win relationship as faculty learn about another cultures and recent immigrants learn more about their adopted land.

Each community has its own set of international organizations and activities some are local and others are affiliated with national organizations. The metropolitan Louisville area has an array of organizations typical for an area with a population of one million people. Faculty can participate in these NGO's in a variety of ways, including: leadership roles, hosting activities, or being a participant in presentations. 


\section{Government-Based International Development Opportunities in the Local Community}

Federal funding is available through a variety of programs to bring international visitors to local communities. These programs, referred to as "Citizen Diplomacy," are designed to work through local NGOs to build sustainable relationships between U.S. citizens and their foreign counterparts. These programs come from a variety of U.S. State Department initiatives in the form of grants to local NGOs. They typically involve individual and groups of foreign professionals visiting their U.S. colleagues. Four national and regional diplomacy programs and their mission are presented in Exhibit 3.

\footnotetext{
“Citizen Diplomacy" Programs - Websites Exhibit 3

http://www.sister-cities.org - Sister Cities International (SCI) is a non-profit citizen diplomacy network creating and strengthening partnerships between U.S. and international communities in an effort to increase global cooperation at the municipal level, to promote cultural understanding, and to stimulate economic development.

http://www.state.gov - The U.S. State Department has several citizen diplomacy programs, including the following:

- http://www.usaid.gov - USAID is a federal government agency that receives overall foreign policy guidance from the Secretary of State. The agency works to support long-term and equitable economic growth and advancing U.S. foreign policy objectives.

- $\quad$ http://exchanges.state.gov/education/citizens/comcon - The goals of the Community Connections program are to provide participants with professional training and exposure to day-to-day functioning of a free market system; encourage public-private partnerships in the NIS by including private sector and government participants; create links between U.S. and NIS regions and communities.

- http://exchanges.state.gov/education/ivp - The International Visitor Program brings participants to the United States from all over the world each year to meet and confer with their professional counterparts and to experience the United States firsthand.
}

http://www.licc.org - Louisville International Cultural Center (LICC) is a non-profit organization dedicated to developing and nurturing cross-cultural relationships among people and institutions in the Greater Louisville area and their counterparts in the world. LICC works with the U.S. State Department programs mentioned above.

http://www.cranehouse.org - Crane House seeks to foster mutual understanding among the peoples of the United States and Asia.

Various State Department agencies sponsor programs with differing objectives. For example the U.S. Information Agency (USIA) sponsors the International Visitor Program (IVP) designed to bring individual or multiregional groups to the U.S. to study current issues affecting their country. The program also hopes to build peopleto-people relationships, friends for the U.S., and long-term professional interactions. For example, one of the many USIA initiatives created a multi-regional group drawn from eight countries to study sustainable economic development. USIA-sponsored groups typically visit local businesses, economic development officials and universities in several communities to learn of U.S. economic development activities.

\section{An Example of University Activities}

Indiana University Southeast (IUS) is a regional campus of Indiana University located in the Louisville, Kentucky metropolitan with approximately 1 million people. IUS has 6,500 students and limited resources to allocate to a variety of programs. This area offers opportunities to faculty for international faculty development. Sizeable foreign investments, significant international trade, large immigrant groups, and the largest UPS package hub in the country provide faculty with opportunities for international exposure. The city also has several active interna- 
tionally oriented NGOs, some of which receive funding from the U.S. State Department programs mentioned earlier. Interested faculty are invited to participate in the activities of the companies and organizations involved in these international endeavors. Faculty may choose to share their professional expertise with the firms and organizations involved, but they are not required to provide these services pro bono.

Each community has different resources, but faculty may still have opportunities to interact with firms or organizations. Listed below are several examples of firms and organizations in the Louisville area that have provided opportunities for IUS faculty and students to participate in international activities.

- $\quad$ The Louisville International Cultural Center (LICC) has been the platform for a variety of international activities. They have been the local host for the International Visitors Program (IVP). Louisville has about 150 IVP visitors a year, which have included an economist from Russia, a pediatrician from Sudan, a newspaper person from Venezuela, a vice-chancellor from Nigeria, an attorney from Austria, an educator from Finland, an economic developer from Malaysia, elected officials from New Zealand and judges from Bosnia and Albania. While the schedule of the visitors is sometimes "tight," there is non-structured time in this program which allows interested faculty time to interact with the visitors.

- $\quad$ LICC has a contract with the U.S./Ukraine Foundation, which is partially funded by the U.S. Agency for International Development (USAID). This contract has allowed Louisville to become a city partner with Donetsk, Ukraine. LICC has lead the effort to do a needs assessment of public services in Donetsk and provide technical assistance for the city. Faculty and community leaders involved with LICC and this project have made several trips to the Ukraine. This has provided faculty an enlightening experience beyond what one could experience on a tour or independent travel.

- In the mid-1990's LICC began working with the U.S. Information Agency (USIA) on a "Business for Russia" program, which brought groups of 20 or so professional people from Russia to the Louisville community for 3-4 weeks to learn about responsibilities of their professional counter parts and to learn about life in the U.S. The program targeted educators, government officials, and entrepreneurs. Visitors stayed with host families and job-shadowed people in the community in similar professions/industries and with similar education. Faculty have taught in this program and have brought visitors to campus to meet with classes and talk to professors. Faculty participation has allowed students and colleagues to gain insights unavailable elsewhere.

- The successor program to "Business for Russia" called "Community Connections" is now bringing people with advanced credentials and significant professional experience to the Louisville community. Several of the initial visitors have returned to the Louisville area to visit former host families and businesses, expand business contacts, or to pursue graduate degrees. Some of the early participants are now sending their children to universities in our area. Louisville has usually hosted three groups a year and a total of more than 500 people have visited the community under this program. Faculty have the opportunity to be host families, to host visitors on campus, or to participate in the visitors' professional programs.

- The World Affairs Council (WAC) has a Louisville chapter, which sponsors seminars and programs on international topics. National speakers sponsored by the WAC are eminently qualified and provide insight into an issue or geographic area. WAC speakers are usually available to speak on university campuses. Additionally, the national WAC organization sponsors overseas trips at nominal cost for members. The trips target a specific region or country and are structured to include meetings with government and business leaders. Slots for these programs are competitive and faculty are invited to apply. The cost for participants on these trips is subsidized.

- $\quad$ The Crane House is a Pan-Asian organization which sponsors programs featuring visiting dignitaries, foreign films, food tasting, cooking classes, literature and arts programs. Many Asians in the Louisville community participate, promote, and sponsor the activities. Additionally, each summer the Crane House sponsors an English as a Second Language (ESL) program in China and other Asian locations. People with 
teaching experience in any discipline are invited to spend six weeks teaching ESL to high school English teachers who are on summer break. The experiences and connections faculty can make through these programs can be invaluable.

- $\quad$ The Sister Cities program provides a U.S. city with many points of connection in their foreign Sister City. Developing those business and educational links can invaluable both for the faculty member and for the respective communities. Trade missions frequently occur between the two cities and these are excellent opportunities for faculty to learn more about the business and culture of another country.

- $\quad$ Rotary International offers international study exchange programs for professionals in the community. Lead by a Rotary member, local professionals spend up to six weeks visiting professional counterparts in another country. This program provides an excellent opportunity for faculty to build face-to-face relationships with professionals in other countries. Rotary also sponsors international exchange programs for high school and college students. Hosting one of these visitors would provide faculty with a one-on-one contact and an opportunity to learn about another culture.

\section{Conclusion}

Business schools and the communities where they reside are increasingly responding to the need to provide international educational experiences to students. Business schools have some flexibility regarding how these services are provided. Success in providing this educational experience depends upon having a well-conceived curriculum and faculty that are knowledgeable in the areas they teach. There are several programs presented in this paper illustrative of the wide variety of opportunities available for faculty to become involved in international activities that will prepare them for this role. It is incumbent on faculty to seek out these opportunities and to become active participants. Faculty involvement may include a faculty member's time or expertise but in most cases only a nominal financial commitment. On some projects, significant international travel expenses will be covered by the sponsoring organizations or agencies. Additionally, business schools will need to recognize the commitment by the faculty members and support them with required resources. An effective plan should lead to successful implementation of a robust and interesting international experience for the students in the business program.

\section{Reference}

1. AACSB - The International Association for Management Education "Standards for Accreditation Business Administration and Accounting - Guidance for Self-Evaluation" (May 9, 2000). 